\title{
Characterization of Anisotropic Damage Behaviour of Recycled Aluminium Alloys AA6061 Undergoing High Velocity Impact
}

\author{
C.S. Ho ${ }^{1 *}$, M. A. Ab Rani ${ }^{1}$, M. K. Mohd Nor ${ }^{1}$, N. Ma'at ${ }^{1}$, M. T. Hameed Sultan ${ }^{2}$, \\ M. A. Lajis ${ }^{3}$, N. K. Yusuf ${ }^{3}$
}

${ }^{1}$ Crashworthiness and Collisions Research Group, Mechanical Failure Prevention and Reliability Research Center (COLORED-MPROVE), Faculty of Mechanical and Manufacturing Engineering, Universiti Tun Hussein Onn Malaysia, Parit Raja, Batu Pahat, 86400 Johor, MALAYSIA

${ }^{2}$ Aerospace Manufacturing Research Center (AMRC), Faculty of Engineering, Universiti Putra Malaysia, Serdang, 43400 Selangor, MALAYSIA

${ }^{3}$ Sustainable Manufacturing and Recycling Technology, Advanced Manufacturing and Material Center (SMARTAMMC), Faculty of Mechanical and Manufacturing Engineering, Universiti Tun Hussein Onn Malaysia, Parit Raja, Batu Pahat, 86400 Johor, MALAYSIA

*Corresponding author

DOI: https://doi.org/10.30880/ijie.2019.11.01.025

Received 27 August 2018; Accepted 12 December 2018; Available online 30 April 2019

\begin{abstract}
It is impossible to ignore the realm of the topics related recycling aluminium scraps. The recycled form of this material can be a good replacement for the primary resources due to the economic and environmental benefits. Numerous investigation must be conducted to establish the mechanical behaviour before the specific applications can be identified. In this research, Taylor Cylinder Impact tests used to investigate anisotropic damage behaviour in recycled aluminium alloy is presented. To be specific, by performing Taylor Cylinder Impact test at velocities ranging from $190 \mathrm{~m} / \mathrm{s}$ to $300 \mathrm{~m} / \mathrm{s}$, anisotropic and damage characteristics can be observed in the samples as a function of the large stress, strain, and strain-rate gradient. The application of Taylor Cylinder Impact test as a technique to validate both the constitutive and dynamic fracture responses in such materials is also discussed. The structure of recycled aluminium AA6061 including the damage initiation and evolution are observed under optical microscope (OM) and scanning electron microscope (SEM). The results revealed that the damage evolution of the material change with the increasing impact velocity. Further, the digitised footprint analysis showed a pronounced anisotropic characteristic of the recycled aluminium AA6061.
\end{abstract}

Keywords: Recyled aluminium, high velocity impact test, digitised profile, anisotropic damage

\section{Introduction}

Aluminium alloys are a standout amongst and most well-known material for some application and products in the market as it has many benefits. There is a considerable measure of sorts, of aluminium. For pure aluminium combinations, it has delicate and low quality properties so with a specific end goal to improve its quality, others components, for example, Magnesium (Mg), Silicon ( $\mathrm{Si})$, copper $(\mathrm{Cu})$, Zinc ( $\mathrm{Zn})$, Lithium (Li) and Manganese $(\mathrm{Mg})$ are included and mixed into an aluminium synthesis [1]-[3]. 
Due to the highly demand of aluminium, this lead to production shortage. Extracting aluminium from bauxite ore is an energy consuming process. The production of primary aluminium is 4,927 thousand metric tons in September 2017 [5]. Based on the observations of the data, the demand for the aluminium is very high therefore the energy for extraction process is highly required and in order to save energy, recycling aluminium is encouraged because it can save about $95 \%$ of energy. This situation leads to production of recycling aluminium. In recycling aluminium, there are two methods that are conventional and direct conversion recycling method. In direct conversion recycling method, hot press forging technique proved that this method have good potential and can bring benefits whether in term of enhancement of metals properties or environmental [5]. Amid recycling process, there is some damage will happen. Damage can be characterized as an accumulation of lasting microstructural changes adjusting thermomechanical properties (e.g., solidness, quality, anisotropy, and so forth) and acquired a material by an arrangement of irreversible physical micro-cracking forms coming about because of the utilization of thermomechanical loading [6], [7]. Damage in aluminium composites is identified with advancing microstructural highlights. The failure procedure in flexible materials is related to the nearby failure of second stage particles, incorporations, intermetallic particles, and precipitates. For instance, Wan et al., [8] demonstrated that the splitting of particles in A357 aluminium composite happens amid plastic deformation. Besides, Balasundaram, Gokhale, Graham, \& Horstemeyer [9] have proposed that damage in aluminium compounds is created by breaking of intermetallic particles, development of voids at broke particles, and void mixture. The investigation verified that the heading of breaks under pressure loading was opposite to the heap course. Along these lines, the approach for distinguishing damage of aluminium composite is essential for evaluating of parts lifespan in the car, aviation, hardware and other metal based industry in light of the fact that the harm is variable that frequently speak to the basic reaction of the material microstructure to the loading conditions forced upon the material.

Besides, the deformation behaviour of anisotropic material undergoing dynamic shock loading also being determined in many applications such as examples in [10]-[16]. Moreover, research study associated with the investigation of the anisotropic influence on material behaviour undergoing finite strain deformation and shock wave can be found in [18]-[26].

In this research, high velocity impact test is one of the most essential approach to investigate the damage progression. The field of impact progression covers a to a great degree extensive variety of circumstance and is important to engineers from various distinctive teach. For instance, production engineers are keen regarding the matter in regard of its application to rapid blanking and opening flanging forms while vehicle makers utilize their comprehension of reaction of structures to impact loading to enhance the execution and security of their items. Notwithstanding, high velocity impact essentially centered on primary metals explore by numerous analyst. Conversely, the recycling metals experience high velocity impact to a great extent unexplored. In research of [26] investigations, most materials demonstrate a huge change in mechanical reaction under expanded rates of stressing. In this section, the survey of investigations of specialists is talked about in light of vary strain rate with respect to primary and secondary materials.

In the field of crash and impact modelling, Taylor Impact Test one of the best approach in investigation of damage progression at high velocity. Taylor Cylinder Impact Test, named after G.I. Taylor who developed the test to screen materials for use in ballistic applications during WW II [27], [28], entails firing a solid cylinder rod of a material of interest, typically 7.5 to $12.5 \mathrm{~mm}$ in diameter by 25 to $40-\mathrm{mm}$ in length, at high velocity against a massive and plastically rigid target. Taylor cylinder impact testing has previously been utilized to probe both the deformation responses of metals and alloys in the presence of large gradients of stress, strain, and strain-rate and as a means to validate constitutive models [29]. This axis-symmetric integrated test provides a readily conducted experimental method by which to examine the large-strain high-strain-rate mechanical behaviour of materials while simultaneously evaluating the accuracy and correct "physics" incorporation in constitutive models [30]. As a matter of course, the final length, cylinder axial profile, and bottom footprint of the Taylor sample in addition to post-mortem microstructural analysis is compared with code simulations to validate the material constitutive model implemented in the application code. In the current study the utility of Taylor cylinders is expanded to examine damage evolution processes in Taylor samples overdriven to high shock pressures and plastic strains. In the Taylor tests deformable flat-nosed cylinders are fired against a fixed quasi-rigid wall to be able to estimate material behaviour at high-strain rates. Alternatively, symmetric Taylor tests are performed where two identical cylinders impact each other. The cylinder impact test is simple, inexpensive, and exhibits large strains, high-strain rates, and elevated temperatures. Taylor test is often used to estimate or to validate high-strain rate material constants under dynamic loading conditions or to demonstrate the quality of numerical codes in computational mechanics.

\section{Specimen Preparations}

Fig. 1 represents the process flow of the specimen preparation. MAZAK vertical centre Nexus 410A-II CNC machine was used for chips production with an average chips size of $5.2 \mathrm{~mm} \times 1.097 \mathrm{~mm}$ x $0.091 \mathrm{~mm}$ using setting as 
shown in Table 1. Then, the chips were cleaned with Acetone solution using ultrasonic bath and dried in $60^{\circ} \mathrm{C}$ thermal oven.

After chips are ready, hot press forging technique was applied to form the recycled specimen. The optimum setting of the forming process was selected referring to previous study by [31]-[33], which performed at $530^{\circ} \mathrm{C}$ and $47 \mathrm{MPa}$ (35.6 tonnes) with 2 hours holding time. Next, the specimen was quenched at $100^{\circ} \mathrm{C} / \mathrm{s}$ quench rate and artificial aging at $175^{\circ} \mathrm{C}$ thermal oven for 120 minutes immediately. The specimen is denoted as T5-temper with going through all these process. Lastly, the electrical wire cutting machine is used for shaping process to form the specimen in cylindrical shape as shown in Fig. 2.

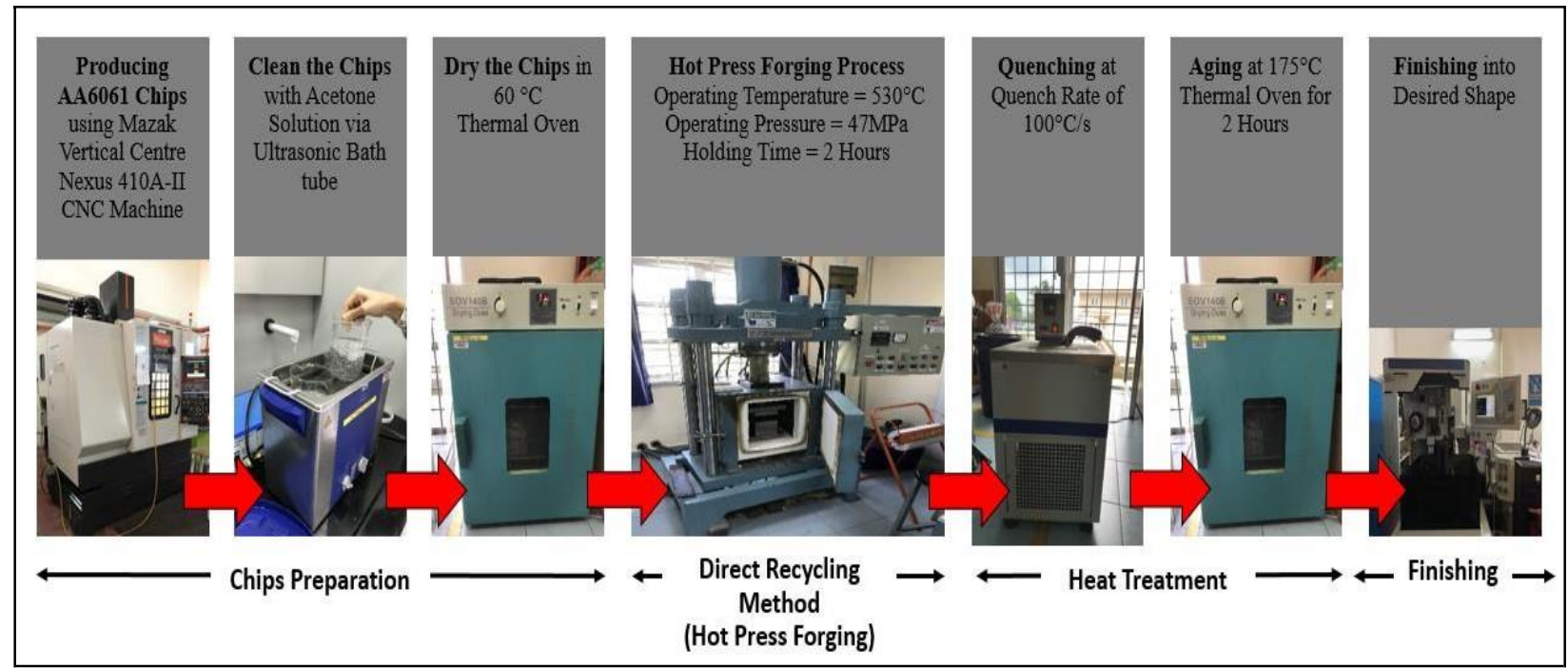

Fig. 1 - Process Flow of Specimen Preparation

Table 1 - CNC Machine Setting for Producing Chips

\begin{tabular}{lc}
\hline \multicolumn{1}{c}{ Parameter } & Value \\
\hline Cutting Speed, v & $377 \mathrm{~m} / \mathrm{min}$ \\
Diameter tool & $10 \mathrm{~mm}$ \\
Feed, $\mathrm{f}$ & $0.05 \mathrm{~mm} /$ tooth \\
Depth of Cut & $1 \mathrm{~mm}$ \\
\hline
\end{tabular}

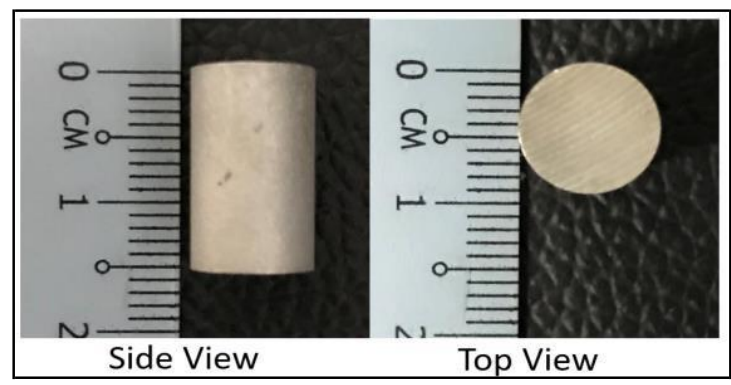

Fig. 2 - Cylindrical Shaped Specimen/ Bullet

\subsection{Experimental Implementation}

Taylor Impact Test is conducted to study the deformation behaviour of recycled aluminium alloy at high strain rate with high velocity where a cylindrical specimen is launched from a smooth bored gun barrel to the rigid massive hardened stainless steel target normally. To minimize the effect of friction the target surface is polished to a mirror-like finished [34]. Fig. 3 shows the Taylor impact gas gun machine used in this research. Pressure is used as a force to launch the bullet toward the target. High speed camera is used to capture the movement and deformation of the bullet towards the target and measure the impact velocity.

The recycled aluminium alloy specimens were made into two different L/D ratio: 1.25 and 1.75 with same diameters $\pm 8.45 \mathrm{~mm}$ but different length at $\pm 10.55 \mathrm{~mm}$ and $\pm 14.75 \mathrm{~mm}$, respectively. Table 2 shows the test matrix for this impact test. 


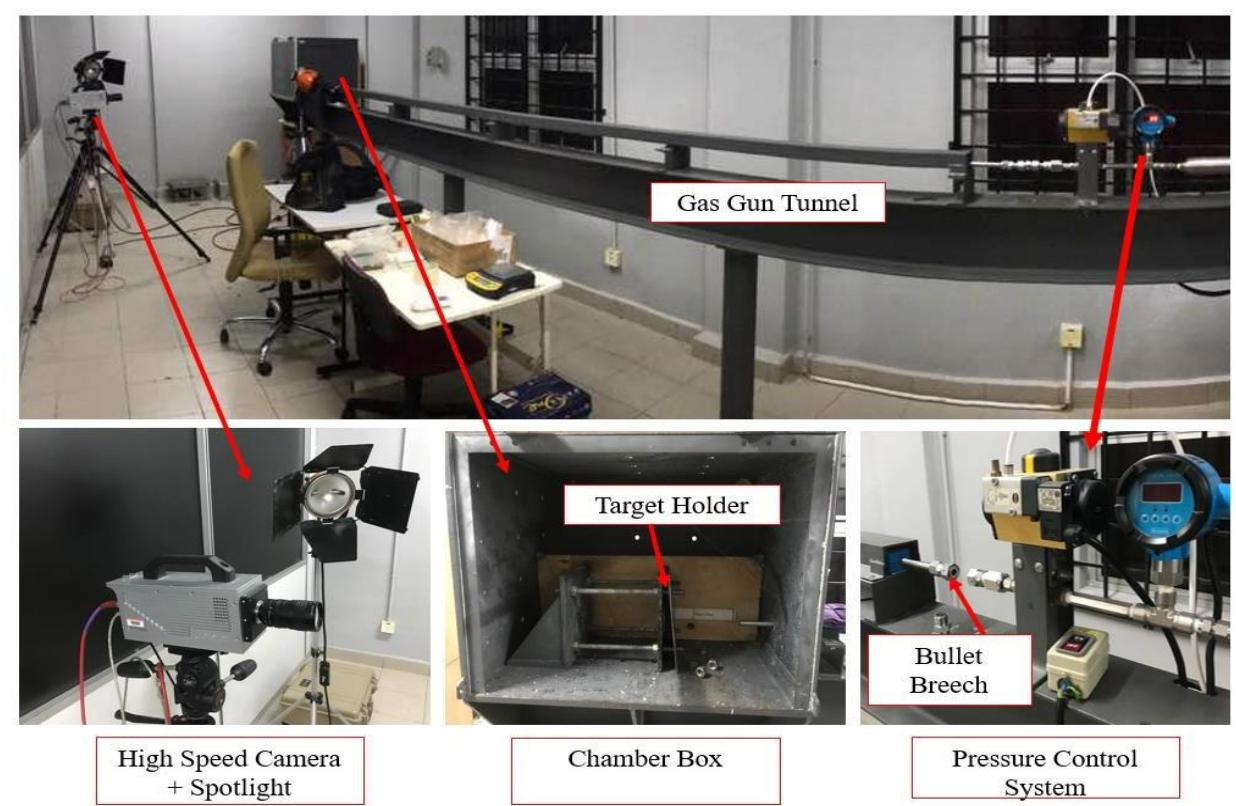

Fig. 3 - Taylor Impact Gas Gun Machine

Table 2 - Test Matrix for Taylor Impact Test

\begin{tabular}{ccccc}
\hline $\begin{array}{c}\text { Pressure } \\
(\text { Bar })\end{array}$ & L/D & $\begin{array}{c}\text { Length, L } \\
(\mathbf{m m})\end{array}$ & $\begin{array}{c}\text { Diameter, D } \\
(\mathbf{m m})\end{array}$ & Label \\
\hline \multirow{2}{*}{6} & 1.75 & 14.75 & 8.45 & $\mathrm{~A} 1$ \\
\cline { 2 - 5 } & 1.25 & 10.55 & 8.45 & $\mathrm{~A} 2$ \\
\hline \multirow{2}{*}{10} & 1.75 & 14.75 & 8.45 & $\mathrm{~A} 3$ \\
\cline { 2 - 5 } & 1.25 & 10.55 & 8.45 & $\mathrm{~A} 4$ \\
\hline \multirow{2}{*}{15} & 1.75 & 14.75 & 8.45 & $\mathrm{~A} 5$ \\
\cline { 2 - 5 } & 1.25 & 10.55 & 8.45 & $\mathrm{~A} 6$ \\
\hline
\end{tabular}

\section{Results and Dicussions}

The high-speed video images captured by the high-speed camera from the impact tests at different pressures and velocity range are shown in Fig. 4. It can be clearly seen that at 6 bar of pressure, the specimen hit the target with projectile angle causing the deformation not equally distributed. This oblique impact phenomenon occurred due to the velocity or speed of the bullet is not high enough to make the projectile strikes the target in direct and straight manner. However, at 10 bar and 15 bar, a better footprint is obtained with direct impact between the specimen and target.

The experimental results are summarized in Table 3. The final diameter/ mushroom diameter is measured and the footprint images are attached. At the lowest impact velocity ranging 190-210 m/s, there are no visible exterior cracks can be observed. However, at impact velocity ranging $220-240 \mathrm{~m} / \mathrm{s}$, some crack is observed at the middle of the sample. At the impact velocity ranging from $240-270 \mathrm{~m} / \mathrm{s}$, obvious crack can be observed and some dimples is spotted on the footprint. From the results, it can be observed that the recycled AA6061 behave anisotropic where the footprint is in ellipse shaped. Sample A6 shows obvious damage among others. Fig. 5 shows a picture of the comparison of mushroomed projectile of A1 and A6 sample before and after impact.

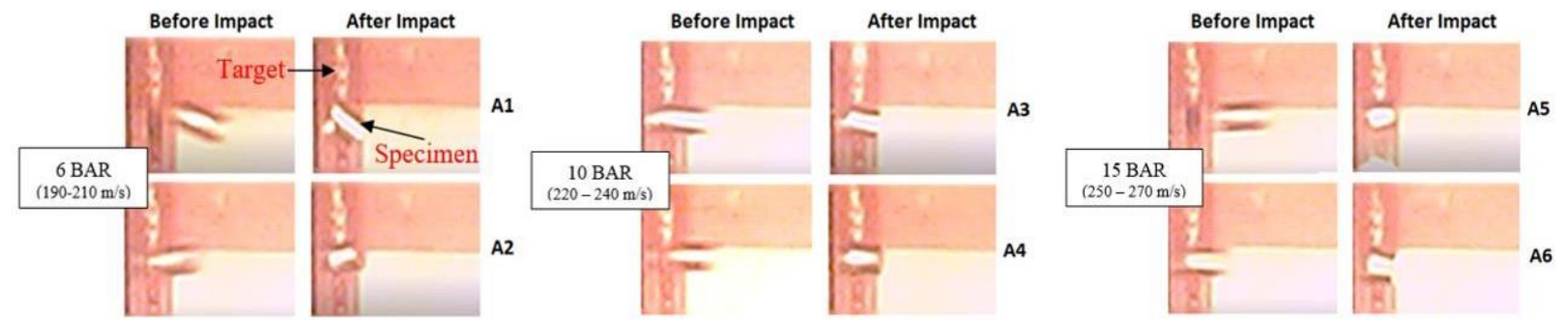

Fig. 4 - High Speed Video Image from Impact Test 
Table 3 - Results of Taylor Impact Test

Label Velocity $(\mathrm{m} / \mathrm{s}) \quad$ Final Diameter $(\mathrm{mm}) \quad$ Footprint After Impact / Fracture Mode

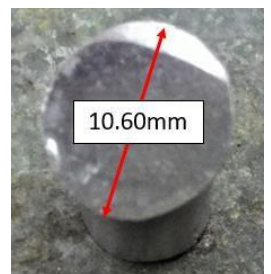

Mushrooming shaped

A2 $206.25 \quad 10.36$

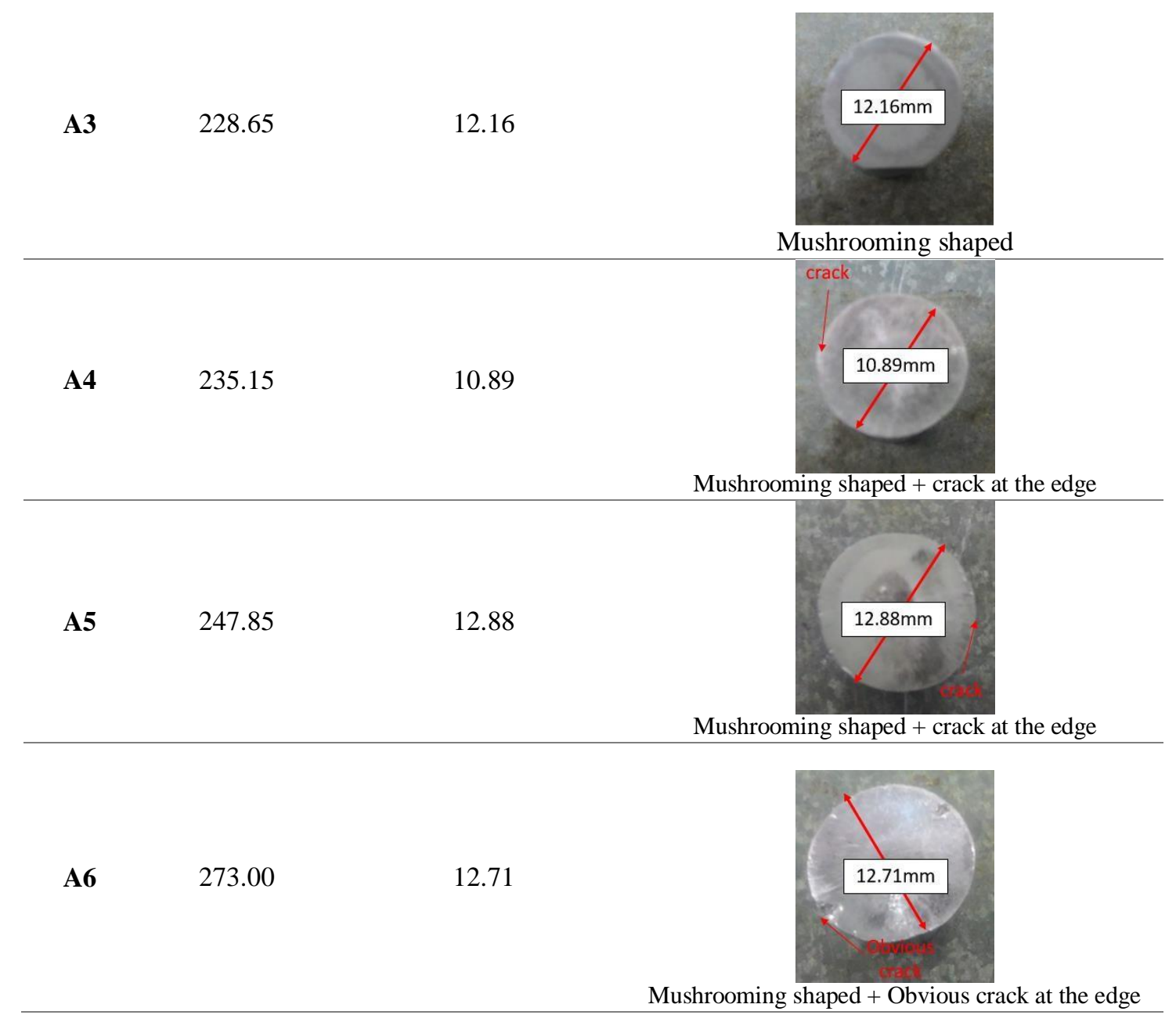



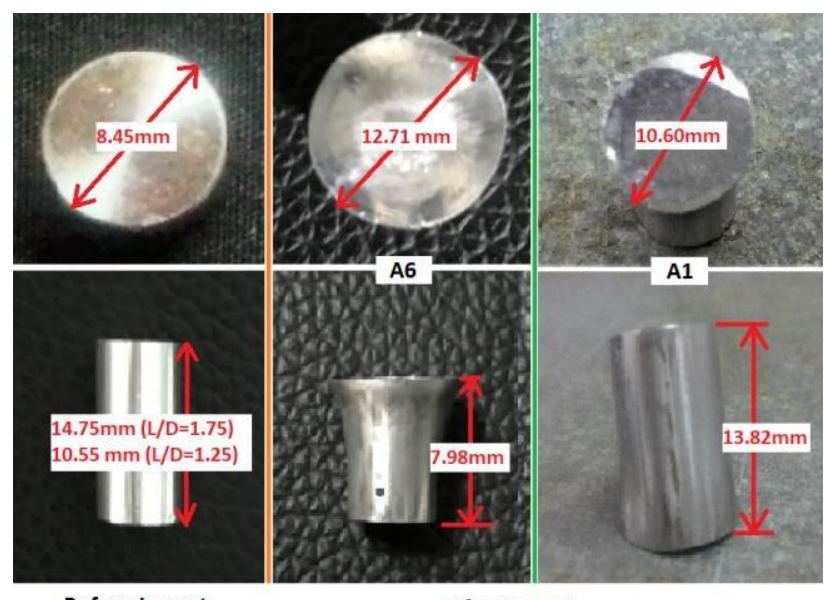

Before Impact

After Impact

Fig. 5 - Deformed Configuration of Samples

From the observation of Fig. 6 and Fig. 7, the fracture occurs at the very edge of the footprint and the centre of footprint shows the crack initiation. This indicates the crack started from the centre spread to the edge of the footprint. The result fracture from Fig. 7 a) is from spallation phenomena in ductile materials. This phenomenon occurs when material undergo excessive impulse loading and high stress due to interaction of stress wave propagation. There are some factors that affect the dynamic growth of void such as heat generated by plastic deformation, inertial effects associated with displacement and wave interactions [26]. The damage at the edge of footprint for A3 is more severe than damage for $\mathrm{A} 1 \mathrm{as}$ the increasing of input velocity for $\mathrm{A} 3 ; \mathrm{v}=228.65 \mathrm{~m} / \mathrm{s}$ while $\mathrm{A} 1 ; \mathrm{v}=193.13 \mathrm{~m} / \mathrm{s}$. The image also shows the closure of the void at higher velocity impact and this indicated that the mushrooming of the specimens produces high stress just behind the impact face on the axis that causing the decreasing of porous zone while increasing the crack damage. Fig. 8 shows the comparison of the SEM micrographs of some samples before and after impact. It can be observed that there are some micro-cracks and micro-voids are initiated and found in the recycled AA6061 then the micro-voids coalescence and growth causing more voids and cracks are formed after impact. Referring to SEM of sample A1 (v=193.13 m/s) and sample A3 (v=228.65 m/s), when the velocity of impact is increasing, the damage getting severe.

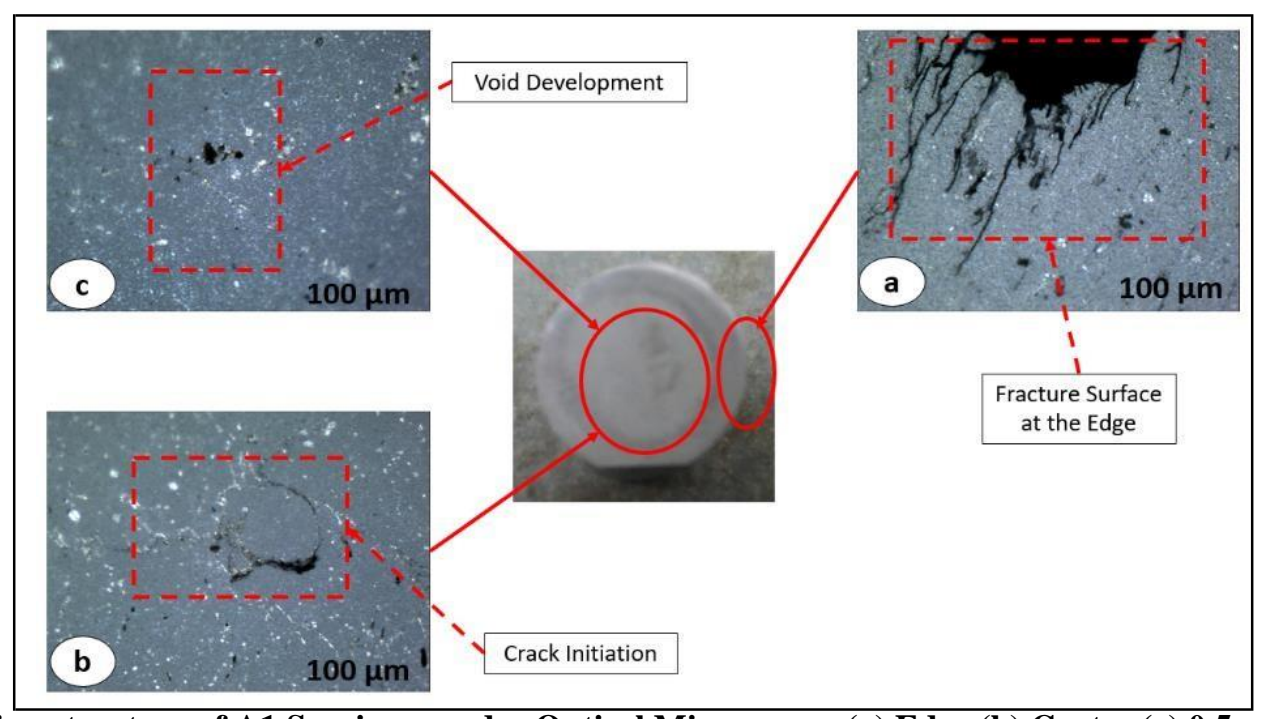

Fig. 6 - Microstructure of A1 Specimen under Optical Microscope: (a) Edge (b) Center (c) 0.5cm Cut Area 


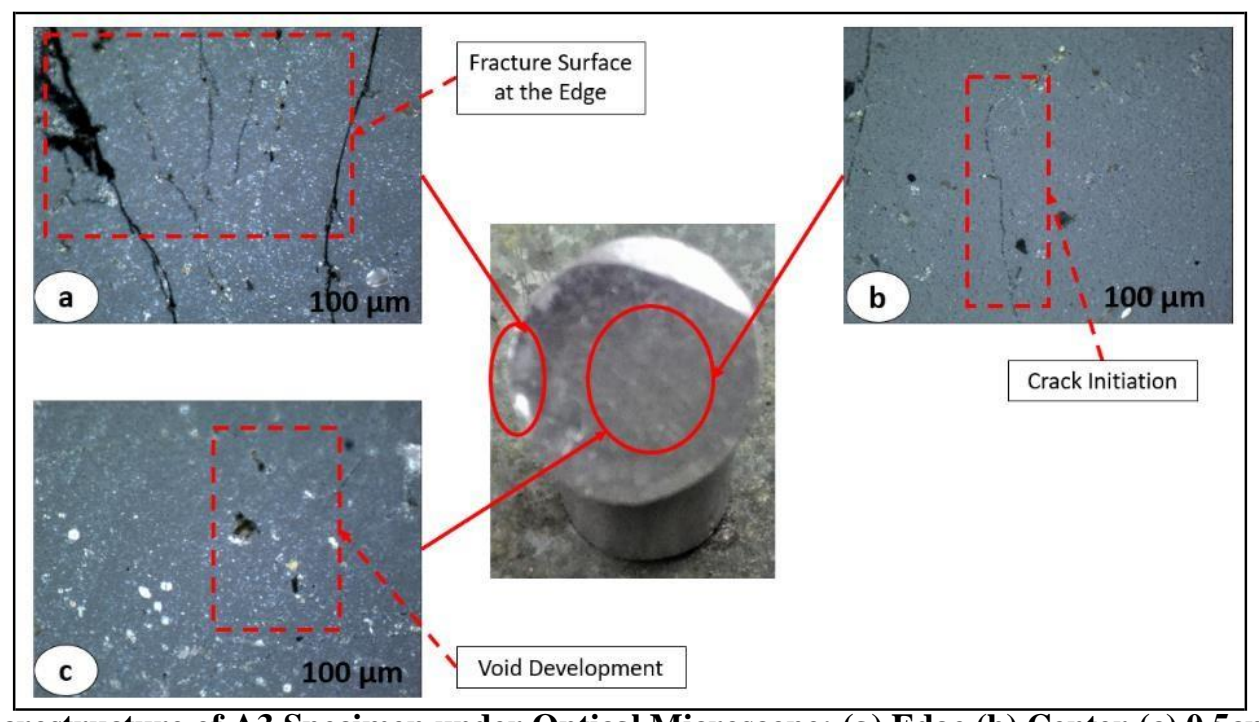

Fig. 7 - Microstructure of A3 Specimen under Optical Microscope: (a) Edge (b) Center (c) $0.5 \mathrm{~cm}$ Cut Area

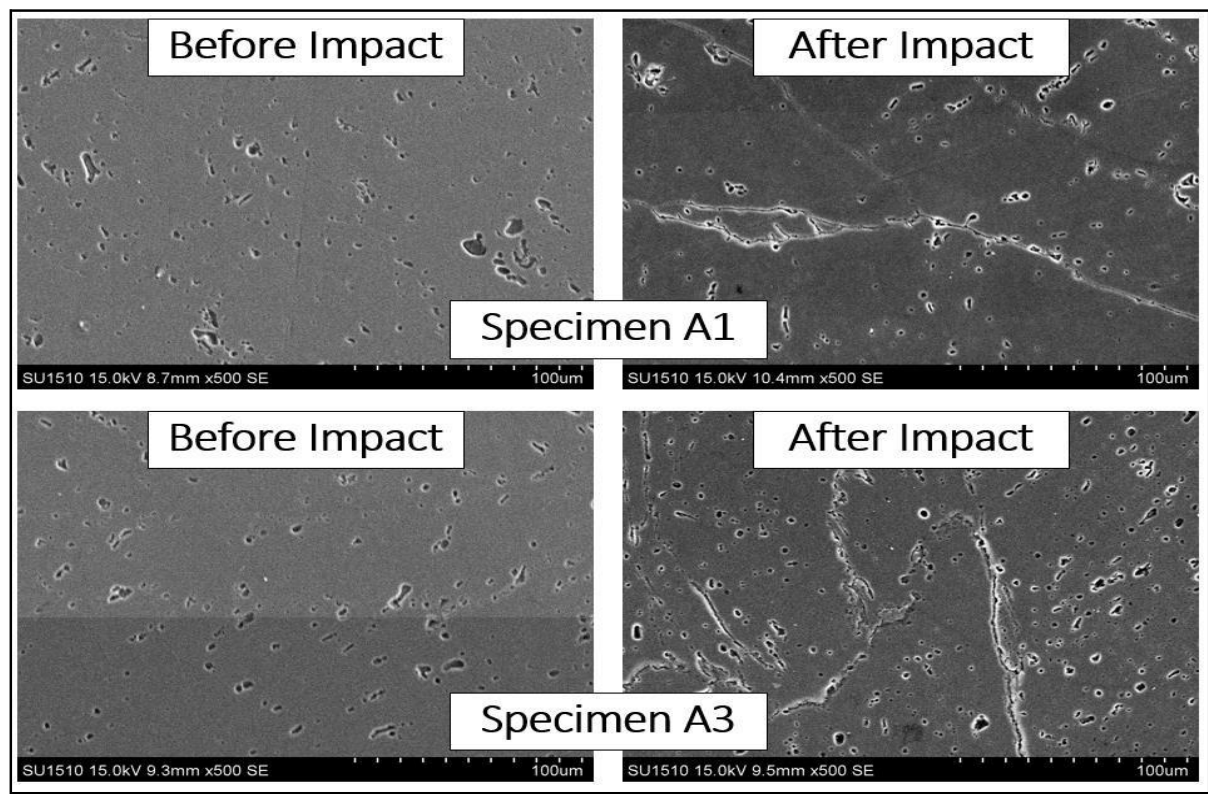

Fig. 8 - SEM Micrographs of Sample A1 and A3 Before and After Impact

In term of L/D ratio, Fig. 9 shows the SEM micrograph of sample tested at same pressure (6 bar), velocity ranging from $190-210 \mathrm{~m} / \mathrm{s}$. The length of the specimen affects the growth of cracks and voids propagation where at lowest $\mathrm{L} / \mathrm{D}$ ratio sample, the voids and cracks growth more serious after impact compare with the one at highest L/D ratio.

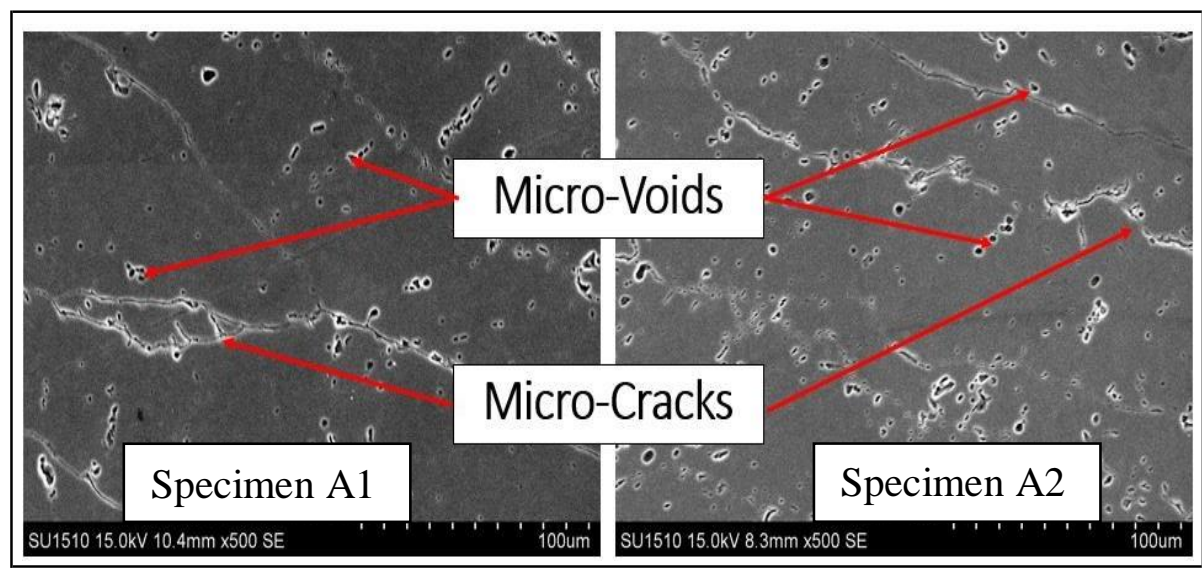

Fig. 9 - SEM Micrographs of Different L/D Ratio at Same Pressure of 6 Bar 
Fig. 10 and Fig. 11 show the plotted of minor and major side profile that impacted with v=228.65m/s and $273 \mathrm{~m} / \mathrm{s}$. From the digitised side profiles, the mushrooming shape or deformation stop at some certain point of y-axis as shown in figure below. Based on Figure 9, at $6 \mathrm{~mm}$ from the footprint the changes of geometry of side profile stop while for Fig. 11 it still has changes until the top of the bullet. This indicated at certain distance, the energy absorbed during the impact are dissipated while for Fig. 11, the changes still occur as the length of the bullet not enough to fully transfer the energy absorbed. So, it can simplify that the longer of length of the bullet the shorter the distance of deformation.

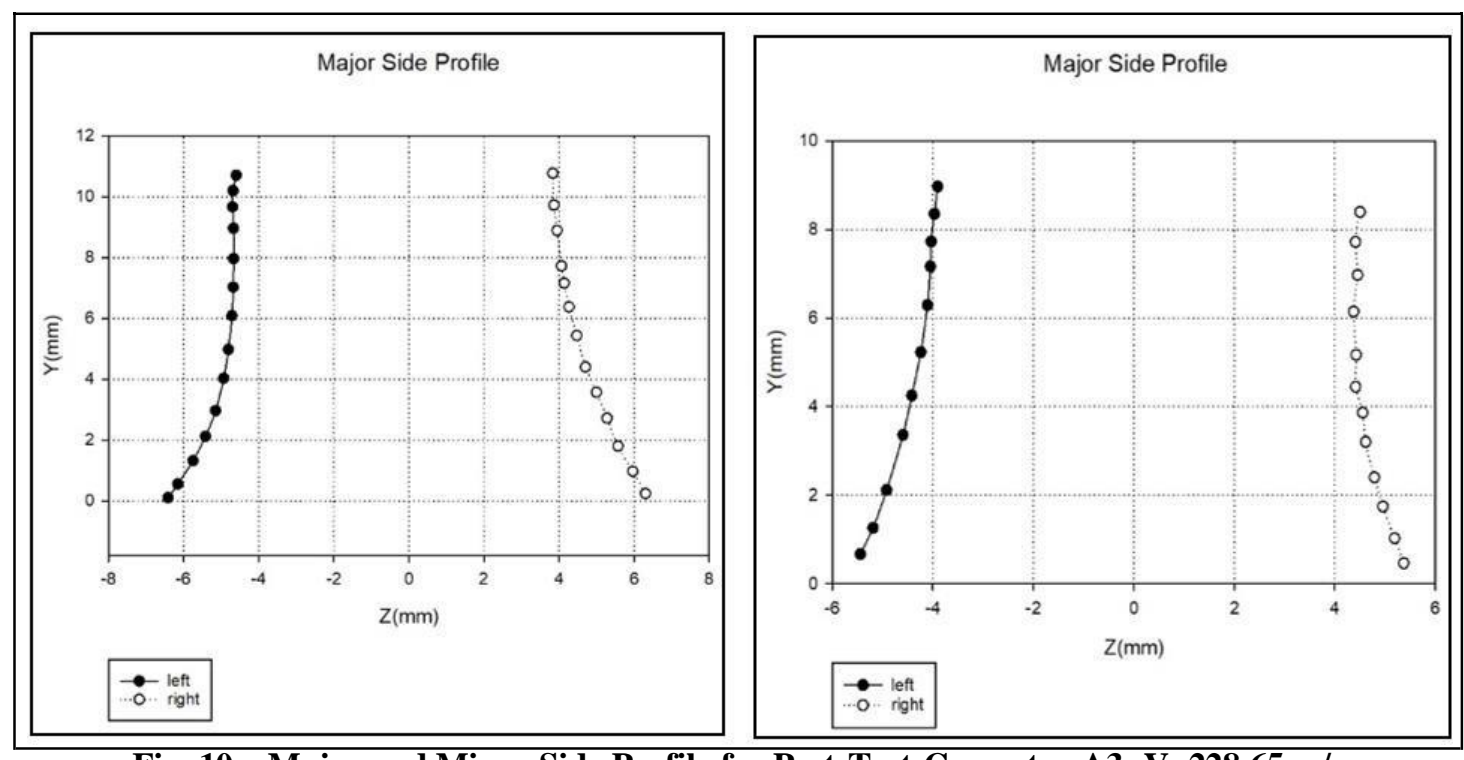

Fig. 10 - Major and Minor Side Profile for Post-Test-Geometry A3; V=228.65 m/s

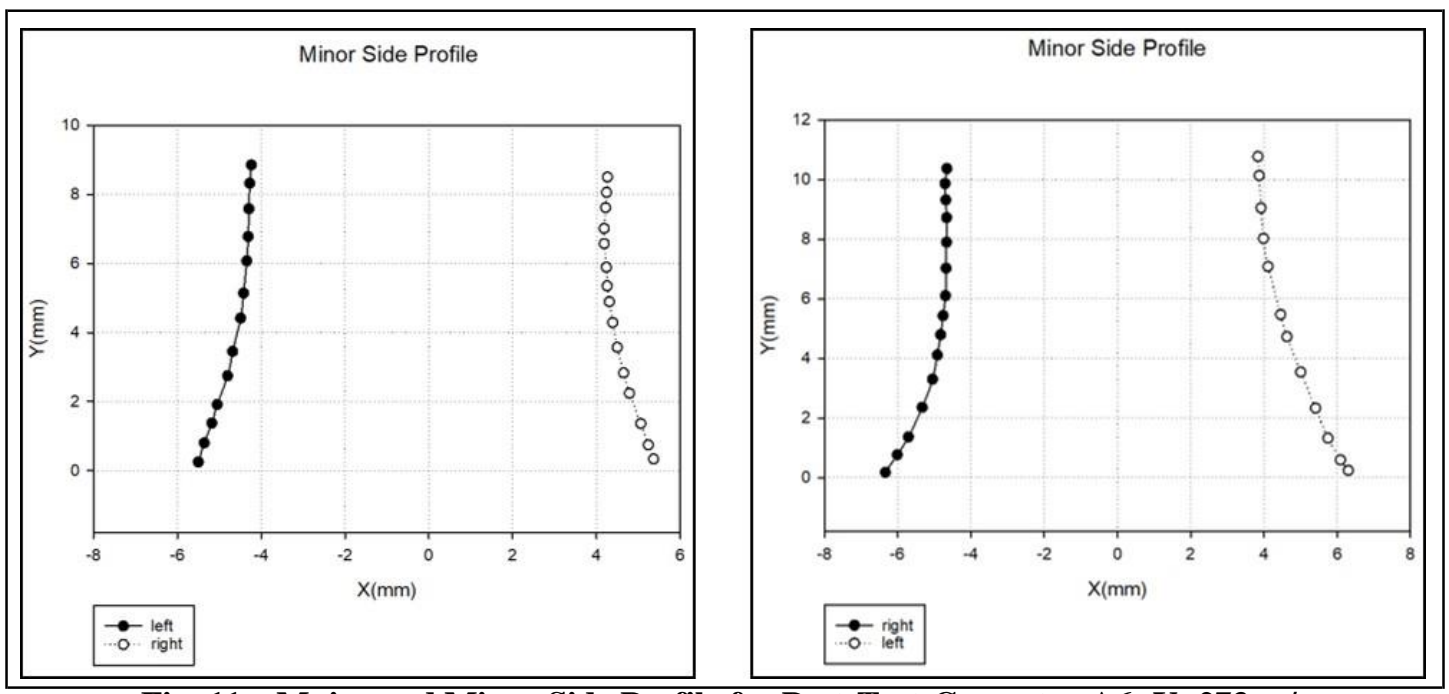

Fig. 11 - Major and Minor Side Profile for Post-Test-Geometry A6; V=273 m/s

Additionally, as shown in Fig. 12, the shape of the deformed region (black dot) becomes an ellipse shape. This proved this recycled AA6061 aluminium is anisotropic materials. During anisotropic deformation, the footprint (face of impact) experiences the variations of deformed direction along the impact axis as can see from the graph at different axis such as major footprint shown the different value along $x$-axis $( \pm 12 \mathrm{~mm})$ and $z$-axis $( \pm 13 \mathrm{~mm})$. This value indicated that the anisotropic materials have different physical properties in different directions as the distance (x, y, $\mathrm{z}$ axis) give different quantitative result. 


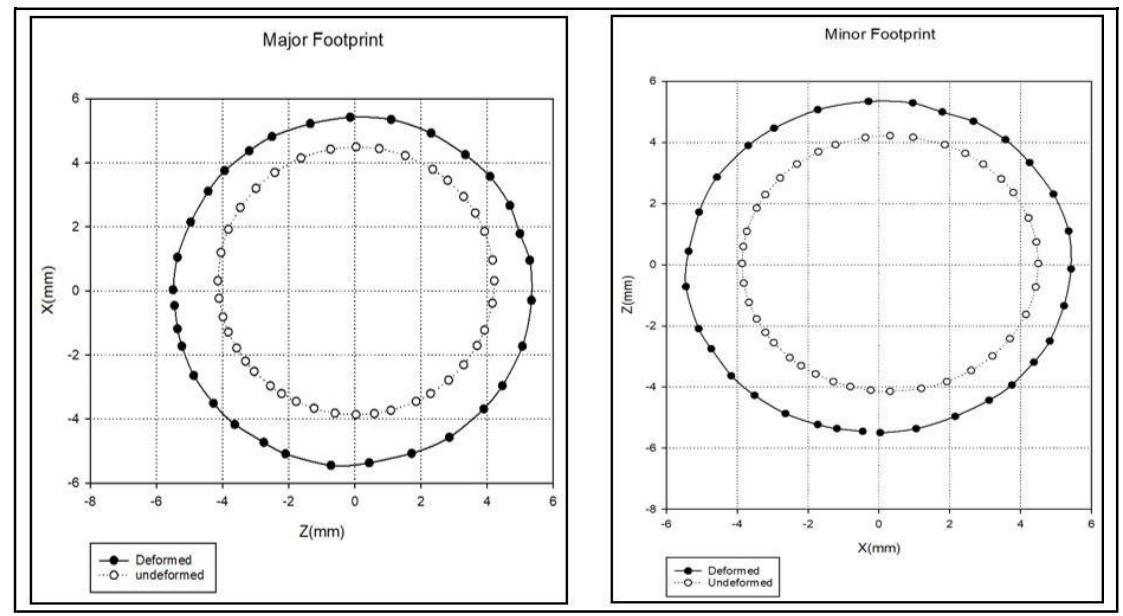

Fig. 12 - Major and Minor Footprint for Specimen A6; V=273 m/s

\section{Summary}

This paper investigates anisotropic damage behaviour in the recycled aluminium alloy AA6061 undergoing high velocity impact using Taylor Cylinder impact test. Microscopic analysis showed the void growth is directly influenced by the level of impact velocity. Further, the void progression and ductile damage seems been influenced by the void developed within the impact area as shown in the microscopic analysis. The microstructural comparison between pre and post test samples reveals the location of the fracture happened at the very edge of the impact face. In addition, a complete mushrooming shape can be simply observed at 15 bars while an oblique impact phenomenon is shown for the impact below 15 bars.

Different $\mathrm{L}_{0} / \mathrm{D}_{0}$ also showed significant influences in the specimen deformation behaviour. It can be seen ratio 1.25 resulted severe deformation compared to ratio 1.75 as the shockwave ceased $6 \mathrm{~mm}$ away from the impact area. This behaviour is clearly observed from the side profile analysis hence confirmed ductile behaviour of the recycled AA6061 aluminium. Finally, the ellipse locus of the footprint showed pronounced anisotropic behaviour of such material. This signals a quite complicated behaviour for constitutive modelling purpose. In general, the findings presented in this paper give a good indication for potential application identification of such recycling materials in the near future. However, this requires further details analysis related to damage and fracture modes characterization before an appropriate constitutive model is developed. This will be great to overcome the shortage of primary resources, reduce material loss, cost, energy consumption and ultimately will bring the country to a greener and waste free society.

\section{Acknowledgement}

Authors wish to convey a sincere gratitude to Universiti Tun Hussein Onn Malaysia (UTHM) and Ministry of Education Malaysia (MOE) for providing the financial means during the preparation to complete this work under Geran Penyelidikan Pascasiswazah (GPPS), Vot U746 and Fundamental Research Grant Scheme (FRGS), Vot 1547, respectively.

\section{References}

[1] N. K. Yusuf, M. A. Lajis, M. I. Daud, and M. Z. Noh, "Effect of Operating Temperature on Direct Recycling Aluminium Chips ( AA6061 ) in Hot Press Forging Process," Appl. Mech. Mater., vol. 315, pp. 728-732, 2013.

[2] M. Irfan et al., "The Effect of Microstructures and Hardness Characteristics of Recycling Aluminium Chip AA6061 / Al Powder on Various Sintering Temperatures," Internaltional J. Integr. Eng., vol. 10, no. 3, pp. 5356, 2018.

[3] P. Ganesh and V. S. S. Kumar, "Finite Element Simulation in Superplastic forming of Friction Stir Welded Aluminium Alloy 6061-T6," vol. 3, no. 1, pp. 9-16, 2011.

[4] S. N. Md Yahaya, C. H. Ng, C. F. Lai, F. Sharrifuddin, and K. H. Grote, "Reviews on the Forming Process of Heat Treatable Aluminium Alloys," Int. J. Integr. Eng., vol. 10, no. 5, pp. 74-79, 2019.

[5] A. Ahmad, M. A. Lajis, N. K. Yusuf, and A. Wagiman, "Hot press forging as the direct recycling technique of aluminium- A review," ARPN J. Eng. Appl. Sci., vol. 11, no. 4, pp. 2258-2265, 2016.

[6] S. Castagne, A. Habraken, and S. Cescotto, "Application of a damage model to an aluminium alloy," ... J. Damage Mech., vol. 10, no. 1, pp. 1-26, 2002.

[7] M. K. M. Nor, R. Vignjevic, and J. Campbell, "Modelling of Shockwave Propagation in Orthotropic Materials," Appl. Mech. Mater., vol. 315, no. April, pp. 557-561, 2013.

[8] B. Wan, W. Chen, T. Lu, F. Liu, Z. Jiang, and M. Mao, "Review of solid state recycling of aluminum chips," Resour. Conserv. Recycl., vol. 125, no. June, pp. 37-47, 2017. 
[9] A. Balasundaram, A. M. Gokhale, S. Graham, and M. F. Horstemeyer, "Three-dimensional particle cracking damage development in an Al-Mg-base wrought alloy," Mater. Sci. Eng. A, vol. 355, no. 1-2, pp. 368-383, 2003.

[10] M. D. Furnish and L. C. Chhabildas, "Alumina Strength Degradation in the Elastic Regime," AIP Conf. Proc., vol. 429, no. 1, pp. 501-504, 1998.

[11] R. Minich, J. Cazamias, M. Jumar, and A. Schwartz, "Effect of Microstructural Length Scales on Spall Behaviour of Copper,” Metall. Mater. Trans. A, vol. 35, no. 9, pp. 2663-2673, 2004.

[12] J. D. Colvin, R. W. Minich, and D. H. Kalantar, "A Model of Plasticity Kinetics and its Role in Simulating the Dynamic Behaviour of Fe at High Strain Rates," Int. J. Plast., vol. 25, no. 4, pp. 603-611, 2009.

[13] G. I. Kanel, E. B. Zaretsky, A. M. Rajendran, S. V. Razorenov, A. S. Savinykh, and V. Paris, "Search for Conditions of Compressive Fracture of Hard Brittle Ceramics at Impact Loading," Int. J. Plast., vol. 25, no. 4, pp. 649-670, 2009.

[14] A. S. Khan and C. S. Meredith, "Thermo-Mechanical Response of Al 6061 with and without Equal Channel Angular Pressing (ECAP)," Int. J. Plast., vol. 26, no. 2, pp. 189-203, 2010.

[15] E. B. Zaretsky and G. I. Kanel, "Plastic FLow in Shock-Loaded Silver at Strain Rates from 10 [sup4]s[sup-1] to 10 [sup7]s[sup-1] and Temperature from 296 K to 1233 K,” J. Appl. Phys., vol. 110, no. 7, p. 073502, 2011.

[16] C. S. Meredith and A. S. Khan, "Texture Evolution and Anisotropy in the Thermo-Mechanical Response of UFG Ti Processed via Equal Channel Angular Pressing,” J. Plast., vol. 30-31, pp. 202-217, 2012.

[17] R. E. Smallman, Modern Physical Metallurgy, 4th ed. London: Butterworths, 1985.

[18] R. Vignjevic, N. K. Bourne, J. C. F. Millett, and T. De Vuyst, "Effects of orientation on the strength of the aluminum alloy 7010-T6 during shock loading: Experiment and simulation," J. Appl. Phys., vol. 92, no. 8, pp. 4342-4348, 2002.

[19] G. T. Gray, N. K. Bourne, and J. C. F. Millett, "Shock Response of Tantalum: Lateral Stress and Shear Strength through the Front," J. Appl. Phys., vol. 94, no. 10, pp. 6430-6436, 2003.

[20] A. S. Khan, R. Kazmi, and B. Farrokh, "Multiaxial and non-proportional loading responses, anisotropy and modeling of Ti-6Al-4V titanium alloy over wide ranges of strain rates and temperatures," Int. J. Plast., vol. 23, no. 6, pp. 931-950, 2007.

[21] A. S. Khan, R. Kazmi, B. Farrokh, and M. Zupan, "Effect of Oxygen Content and Microstructure on the Thermo-Mechanical Response of Three Ti-6Al-4V alloys: Experiments and Modeling Over a Wide Range of Strain-Rates and Temperatures," Int. J. Plast., vol. 23, no. 7, pp. 1105-1125, 2007.

[22] M. Sitko, B. Skoczen, and A. Wroblewski, "FCC-BCC Phase Transformation in Rectangular Beams Subjected to Plastic Straining at Cryogenic Temperatures," Int. J. Mech. Sci., vol. 52, no. 7, pp. 993-1007, 2010.

[23] M. K. Mohd Nor, "The Development of Unique Orthogonal Rotation Tensor Algorithm in the LLNLDYNA3D for Orthotropic Materials Constitutive Model,” Aust. J. Basic Appl. Sci., vol. 9, no. 37, pp. 22-27, 2015.

[24] M. K. Mohd Nor, "Modelling inelastic behaviour of orthotropic metals in a unique alignment of deviatoric plane within the stress space," Int. J. Non. Linear. Mech., vol. 87, no. February, pp. 43-57, 2016.

[25] M. K. Mohd Nor, "Modeling of Constitutive Model to Predict the Deformation Behaviour of Commercial Aluminum Alloy AA7010 Subjected to High Velocity Impacts," ARPN J. Eng. Appl. Sci., vol. 11, no. 4, pp. 2349-2353, 2016.

[26] V. Panov, "Modelling of Behaviour of Metals at High Strain Rates," PhD Thesis, Cranfield University, 2006.

[27] G. Taylor, "The Use of Flat-Ended Projectiles for Determining Dynamic Yield Stress. II. Tests on Various Metallic Materials," Proc. R. Soc. A Math. Phys. Eng. Sci., vol. 194, no. 1038, pp. 300-322, 1948.

[28] N. Abdul Rahman, S. Abdullah, M. F. Abdullah, M. Z. Omar, Z. Sajuri, and W. F. Hakim Zamri, "Ballistic Limit of Laminated Panels with Different Joining Materials Subjected to Steel-Hardened Core Projectile," Int. J. Integr. Eng., vol. 10, no. 5, pp. 8-14, 2019.

[29] P. J. Maudlin, J. F. Bingert, J. W. House, and S. R. Chen, "On the modeling of the Taylor cylinder impact test for orthotropic textured materials: Experiments and simulations,” Int. J. Plast., vol. 15, no. 2, pp. 139-166, 1999.

[30] A. E. Ismail, S. Jamian, K. Kamarudin, M. K. Mohd Nor, M. N. Ibrahim, and M. A. Choiron, "An Overview of Fracture Mechanics with ANSYS," Int. J. Integr. Eng., vol. 10, no. 5, pp. 59-67, 2019.

[31] A. Ahmad, M. A. Lajis, and N. K. Yusuf, "On the Role of Processing Parameters in Producing Recycled Aluminum AA6061 Based Metal Matrix,” Materials (Basel)., vol. 10, no. 1098, pp. 1-15, 2017.

[32] N. K. Yusof, "A New Approach of Direct Recycling of Aluminium Alloys Chips (AA6061) in Hot Press Forging Process," Universiti Tun Hussein Onn Malaysia, 2013.

[33] C. S. Ho et al., "Damage Initiation and Evolution Analysis of Hot Extruded Recycled Aluminium Alloys ( AA6061 )," in International Conference on Materials Characterization, 2017, pp. 1-7.

[34] Z. Cao, "Investigation of Taylor Impact Test of Isotropic and Anisotropic Material Through Geometrical Characteristics of Specimens," Degree of Master Thesis, University of Alabama, 2010. 